\title{
California Wildfire Exposure, Vulnerability, and Mental Health: Who gets to recover and who does not?
}

\author{
Muhammad Hassan Bin Afzal \\ Department of Political Science \\ Kent State University \\ Kent, Ohio, 44242 \\ mafzal@kent.edu \\ https://orcid.org/0000-0001-8192-0885
}

Corresponding Author:

Muhammad Hassan Bin Afzal

Department of Political Science

Kent State University

Kent, Ohio, 44242

mafzal@kent.edu

https://orcid.org/0000-0001-8192-0885

Final Word Count: 4800 


\section{Table of Contents}

\begin{tabular}{ccc}
$\frac{\text { Chapter }}{\text { Number }}$ & \multicolumn{1}{c}{ Chapter Title } & \multicolumn{1}{c}{ Page Number(s) } \\
$\underline{\mathbf{0 1}}$ & Introduction & $5-6$ \\
$\underline{\mathbf{0 2}}$ & The Impacts of Wildfires in California & $6-8$ \\
$\underline{\mathbf{0 3}}$ & The Vulnerability Determinants & $9-10$ \\
$\underline{\mathbf{0 4}}$ & Study Design and findings & $11-14$ \\
$\underline{\mathbf{0 5}}$ & The Significance of the Study & $15-16$ \\
$\underline{\mathbf{0 6}}$ & Limitations of the Study & 16 \\
$\underline{\mathbf{0 7}}$ & Key Policy Recommendations & 16 \\
$\underline{\mathbf{0 8}}$ & Conclusion and Future Works & $17-19$ \\
& Works Cited & $19-24$ \\
& Appendices & $25-28$
\end{tabular}




\section{List of Figures}

Figure

Number

$\underline{01}$

$\underline{\mathbf{0 2}}$

03 The Cumulative Findings of Quantitative Studies on CA Wildfire and Mental health

04 The Cumulative Findings of Qualitative Studies on

Wildfire and Mental health

$\underline{05}$ $\underline{\text { Figure Title }}$

The number of properties with a severe danger of

wildfire damage (Verisk, 2020) $\underline{\text { Page }}$

Number(s)

6

9

12

14

symptoms

\section{$\underline{\text { List of Appendices }}$}

$\underline{\text { Appendix }}$

Number

$\underline{01}$

\section{$\underline{\text { Appendix Title }}$}

Full Scope of the Research (Intersection of CA

Wildfire, Mental Health, and Vulnerability

Determinants

$\underline{\mathbf{0 2}}$

List of Quantitative Studies and their findings

26

$\underline{\mathbf{0 3}}$

List of Qualitative Studies and their findings

27

$\underline{04}$

Vulnerable Populations vs. Count of Symptoms

28 


\title{
California Wildfire Exposure, Vulnerability, and Mental Health: Who gets to recover and who does not?
}

\author{
Muhammad Hassan Bin Afzal
}

\begin{abstract}
:
One of the various aftereffects of persistent climate change is an upsurge in the frequency, severity, and effect of wildfires on the wellbeing of suffering communities. The destruction and wreckage of one's home, properties, and the surrounding neighborhood, as well as the threat to one's psychological safety and the safety of loved ones, can have long-term effects on survivors' mental health. The central goal of this study, therefore, is threefold. Firstly, identify the significant qualitative and quantitative studies that examine the impacts of wildfire on mental health. This study mainly focuses on studies that capture the effects of wildfire, smoke, and air quality in California and how that affected the local communities based on their vulnerability determinants. Secondly, the study examines both types of studies to find common grounds regarding the most vulnerable population and their mental health, their ability to seek professional help, and barriers to the road to recovery. Finally, this study provides evidence-based strategies for including more vulnerable members of society in receiving sufficient and timely psychological care to recover from PTSD, trauma, distress, and hopelessness. Migrant farmworkers, particularly younger female Hispanic and indigenous workers, suffer from the wildfire's long-term stress, PTSD, depression, and emotional distress. Furthermore, the continued COVID-19 deepens the gap, social stigma, and barriers to receiving sufficient mental health care to recover and rehabilitate traumatic wildfire exposure. A localized mental healthcare support system based on equity, with flexible infrastructure and greater accessibility, promises to be more efficient and advantageous for underrepresented and vulnerable individuals seeking mental health treatment and quick recovery.
\end{abstract}

Keywords: California Wildfires, Migrant farmworkers, Indigenous Community, Mental health Support, Access to Healthcare, Equitable Healthcare Access 


\section{Graphical Abstract:}

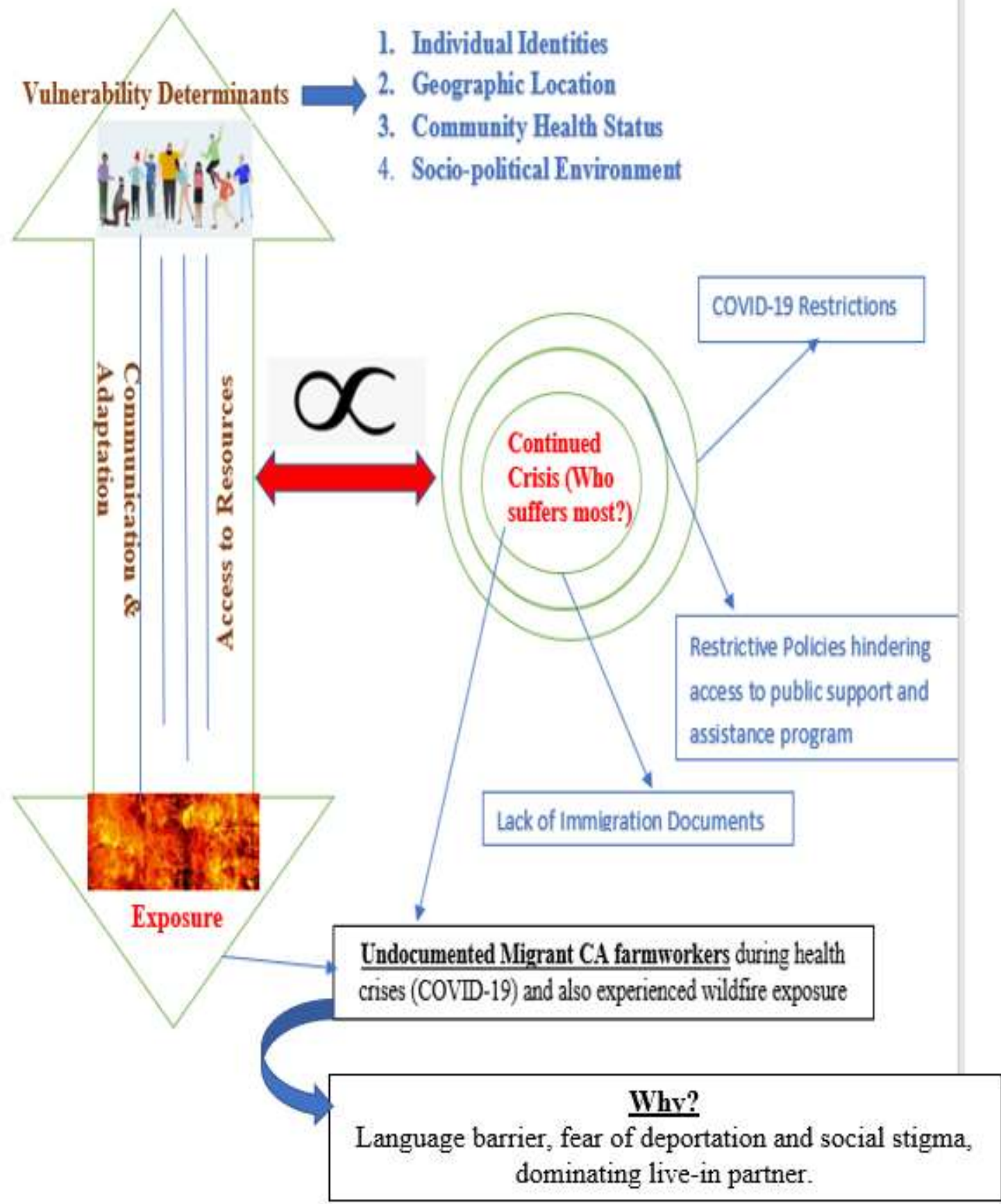




\section{Introduction:}

The frequency, duration, and severity of wildfires and the length of fire seasons are all escalating due to climate change. The smoke from the fires can linger for weeks or months in towns hazy from the flames. Wildfire smoke was released for several months in Australia during the 2019-2020 fire season and in California during the 2020 season. The effects of urban fine particle air pollution (PM2.5 and PM10) from industrial and motor vehicle emissions on population mental health have been examined, and wildfires may have equivalent or different toxicities (Brook \& Constible, 2020).

Climate change causes warmer temperatures, changes in wind speed, and precipitation patterns, all of which are required for wildfire initiation and transmission. Warmer temperatures, longer summers, and scorching heatwaves are all consequences of climate change, and they all contribute to increased concern about and frequency of wildfires. According to the latest article released by the US Department of Interior, roughly $85 \%$ of wildfires in the United States are initiated by human actions (NPS, 2020; Short, 2020). According to Verisk's 2019 Wildfire Risk Analysis, 4.5 million households in the United States are in danger of catastrophic or severe wildfires, including over 2 million in California, 0.71 million in Texas, and 0.37 million in Colorado. According to the Verisk Risk Analysis assessment, more than 3 million homes and businesses in Colorado, Texas, and California are in danger of wildfire damage at any one moment. The bulk of these residences are occupied by impoverished, vulnerable, and underserved communities with less efficient wildfire countermeasures and access to adequate resources to combat and reduce the impacts of wildfire, smoke, and healthcare support (Verisk, 2020).

There were four quantitative studies and twelve qualitative studies focusing on wildfires in the United States. From 2007 to 2020, twelve quantitative research were evaluated to identify the 
impact of wildfires on mental health. In addition, twenty-three qualitative research articles published between 1990 and 2021 were assessed and analyzed to better understand the effects of wildfire on mental health. All the findings that examined the impacts of wildfire smoke and air quality in the United States, emphasizing Californian wildfires, found severe mental health consequences for the affected communities. The following section explores the historical trends of wildfires in the USA and their detrimental socio-economic impacts.

\section{The Impacts of Wildfires in California}

Nearly ninety percent of the total of California's agricultural workers were not born in the United States. They were born in Mexico and other Central American nations and moved to California owing to diverse socio-political and personal conditions. Despite conflicting estimates, it is believed that more than half of those employees are undocumented and do not have access to health care or public assistance due to lack of documents, perceived fear of deportation, and restrictive social and immigration policies. Undocumented workers have long been vulnerable, but harsh political rhetoric and legislative reforms have further alienated them in recent years, with disastrous repercussions for their health, livelihood, and well-being (Galarneau, 2013; Jordan, 2020).

The National Interagency Fire Center recently estimated 47,057 wildfires from January 1 to October 12, 2021, up from 45,635 over the same time in 2020. By October 12, 2021, around 6.5 million acres were burnt, compared to 8.3 million over the same period in 2020 . On October 12 , nine states reported 45 significant fires, including 14 in Idaho and ten in California. The Bootleg Fire in Oregon consumed 413,7617 acres before being extinguished. The Dixie fire in California, which started on July 13 and burnt 963,309 acres, was 94 percent controlled on October 12 (EPA, 2020; NICC, 2020). 
Based on the most recent Calfire figures, the Dixie fire is the second-largest wildfire on record in California, trailing only the August Complex Fire, which burned over a million acres in August 2020. Across five counties, the Dixie fire has destroyed 1,329 structures and damaged 95 others. The Monument Fire, which has burned over 223,000 acres, is now 93 percent contained. The Caldor fire burned over 222,000 acres and is currently 98 percent contained, destroying 1,003 structures and damaging 81 others. The Beckwourth complex fire comprised the Sugar Fire and the Dotta Fire in Plumas County, burned 105,670 acres. Over 7,100 fires have burned nearly 2 million acres in California so far in 2021 (EPA, 2020; NICC, 2020). Figure-01 depicts the high and/or extreme risks of wildfires in different states.

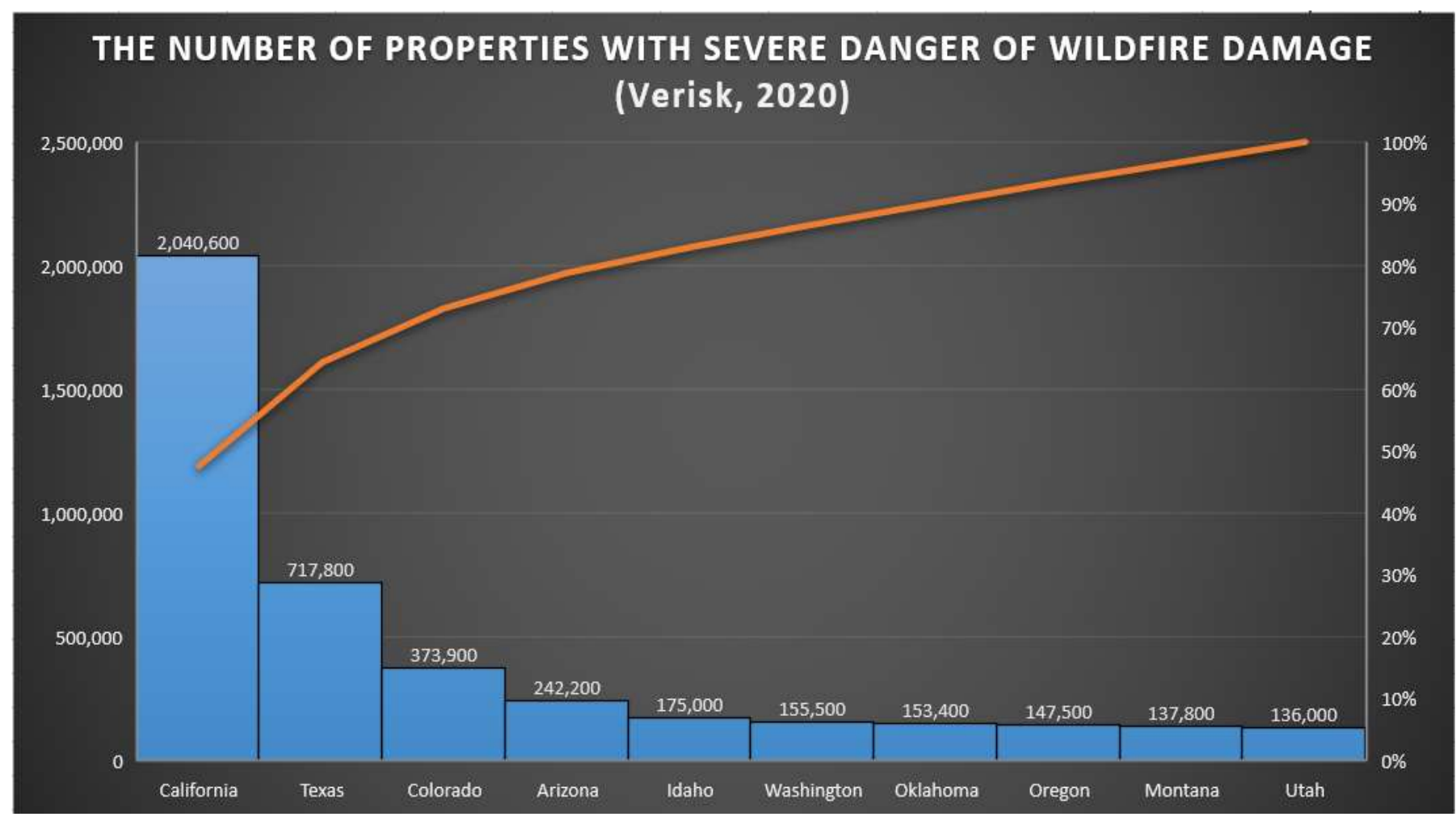

Figure 1: The number of properties with a severe danger of wildfire damage (Verisk, 2020)

Due to the geographic location, high wind, human activities, and climate change, California experiences the most wildfire incidents per year. The number of wildfires continues to rise due to warmer temperatures and drier plants, which kindle to the wildfire (Pierre-Louis \& Schwartz, 
2021; Rosenberg, 2020; Seattle Times, 2020). Rising temperatures, drier weather throughout the summer, and an increase of droughts lead plants and trees to grow drier, acting as fuel and spreading the fire more swiftly. In recent years, most California wildfires have been caused by continuing climate change and irresponsible human activity. Figure-2 provides detailed geographical differences in the growing number of wildfires in California (NASA, 2021).

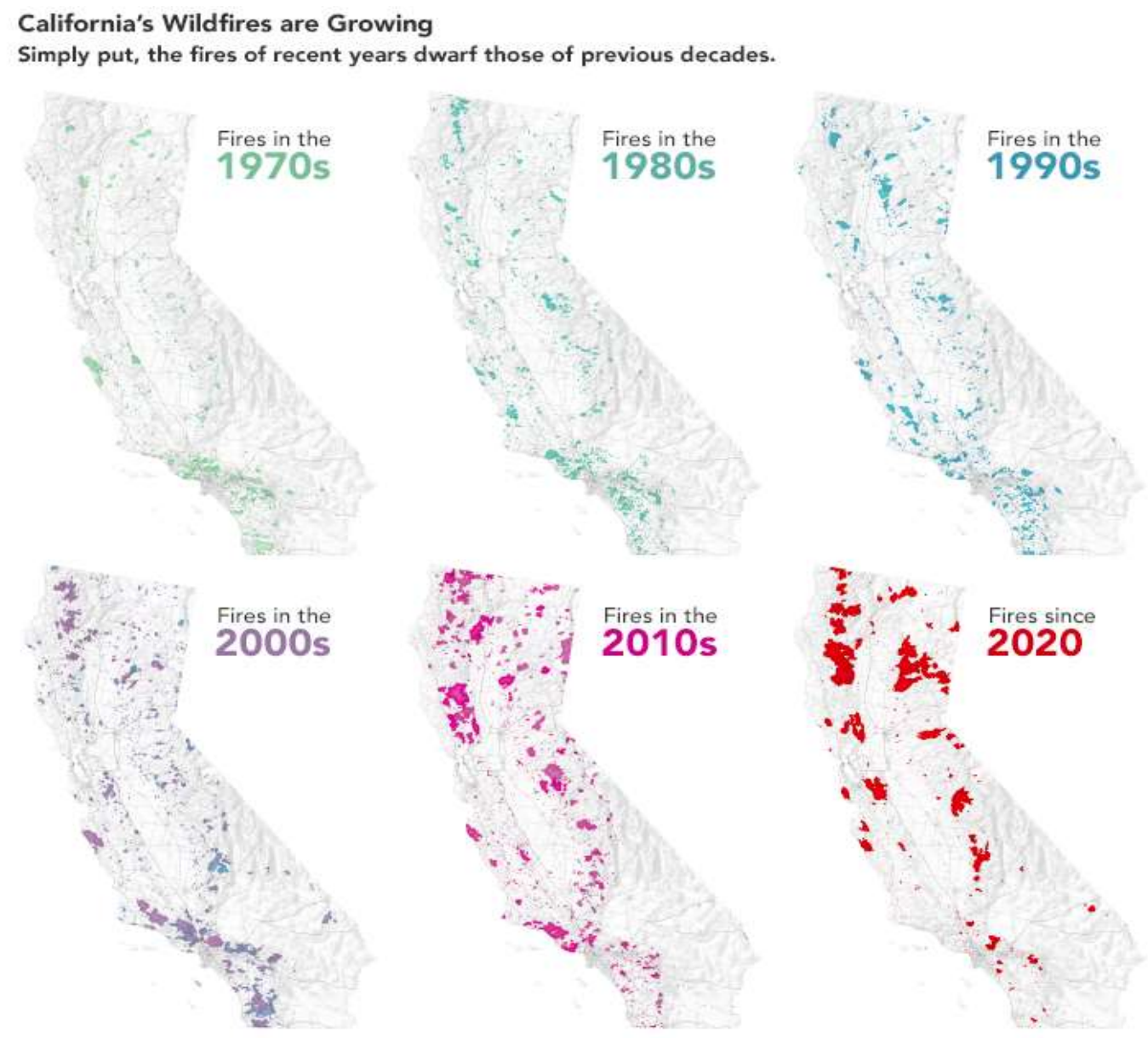

Figure 2: The increasing number of wildfires in California (NASA, 2020)

Figure 2 illustrates how large wildfires have burned in California in recent summers, with the intensity, duration, and damage escalating. California Department of Forestry and Fire Protection (Cal Fire) estimates that eight of the state's ten largest fires on record have happened in the previous five years, as have twelve of the top twenty (Cal Fire). The twelve Californian 
wildfires have burned about four percent of the States' total land area, roughly Connecticut's size (NASA, 2021; Pierre-Louis \& Schwartz, 2021; Seattle Times, 2020). The following section describes the study method, analysis, and impacts of increasing wildfires in California and how they affect local communities based on their vulnerability determinants.

\section{The Vulnerability Determinants:}

Climate Vulnerability (CV) determining factors are a significant concept in natural hazards and disaster mitigation management, ecology, public health, poverty, and climate change. Individuals' vulnerability to climate change is characterized by their exposure to the disaster, physical health, immigration status, financial security, mental health and well-being, and adaptation capability. Due to adverse climate change, vulnerability determinants are broadly categorized into four sections (Dubrow, 2021). These factors are discussed below.

\section{Intersectional Individual Identities:}

Human beings are a collection of intersectional social identities, where an individual's identity consists of several intersecting characteristics, such as gender identity, gender expression, race, ethnicity, class (past and present), religious beliefs, sexual identity, immigration status, and sexual expression (Coaston, 2019; Dubrow, 2021). Specifically, both individual-level health status and immigration status play a significant role in determining the ability to get support and road to recovery for the individuals during disasters and crises induced by climate change (Afzal, 2020, 2021b). The immigration status combined with current immigration policies in that region determines mobility, access to resources, the probability of recovery, and adequate institutional support in navigating climate change-induced crises and disasters such as wildfires in California (Afzal, 2019, 2021a). 


\section{Impacts of Geographic Location:}

Certain geographic regions are more prone to climate change-induced crises compared to other regions. California, Texas, and Colorado are the top three states in the USA that are more prone to suffer from climate change and have a higher probability of experiencing property damage (see Figure-01).

\section{Community Health Status}

The availability and accessibility of healthcare services significantly influence the vulnerability of persons in that community during climate-change-induced crises and catastrophes. Certain places have more resources and healthcare support due to current social policies, public perspectives, legislative preferences, and the socio-economic circumstances of the community. Unfortunately, migrant farmworkers in California face a grossly unfair reality. Migrant farmworkers in California typically live in underserved areas with restricted access to healthcare and institutional welfare programs due to immigration, healthcare, and public legislation (Care et al., 2003; Castillo, 2020).

\section{$\underline{\text { Socio-political Environment }}$}

The social-political framework of a community also influences individual vulnerability during crises and disasters. Elected legislators, politicians, and policy entrepreneurs have the unique ability to set agendas, debate policies, and implement laws and regulations that may improve access to adequate health care and socio-economic support for specific individuals during climate change-induced crises or vice versa (Afzal, 2021b, 2017).

The following section discusses the study design and findings from both quantitative and qualitative approaches in finding the connections between wildfire exposure and impacts on 
mental health. Most of the US-based studies focus on Californian wildfires and their effects on the suffering local community members.

\section{Study Design and findings:}

I examined 11 quantitative and 23 qualitative studies focusing on the intersectional approach between wildfires, vulnerability determinants, and mental health. I investigated the Google Scholar database for publications and study findings that reflected the influence of wildfire smoke and the air quality index on the mental health of local populations. On the second stage of my data finding, I primarily focused on research findings that capture wildfires' impact on Californian residents.

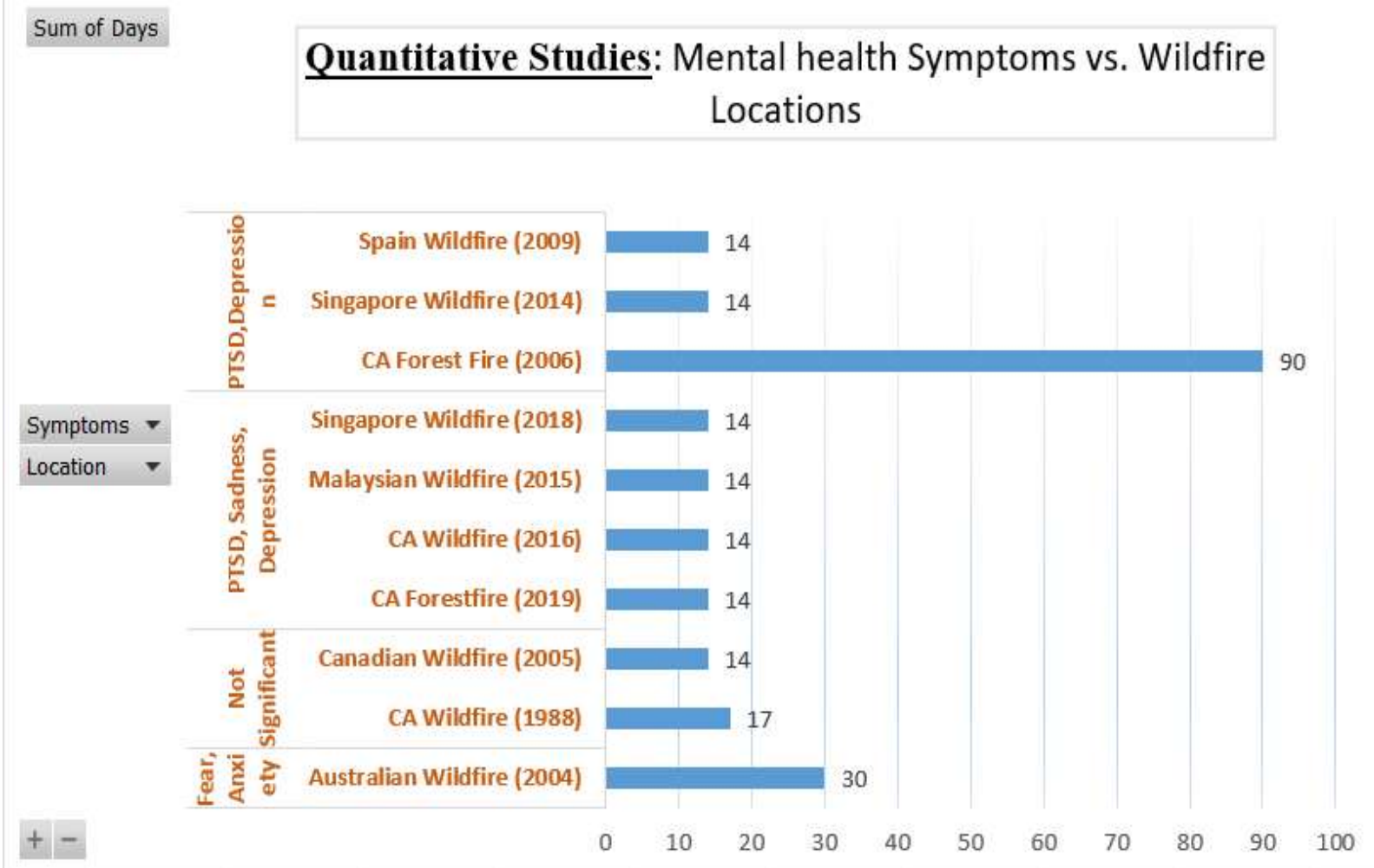

\section{Figure 3: The Cumulative Findings of Quantitative Studies on CA Wildfire and Mental health}

Table-1 in the appendix outlines the detailed findings of the quantitative studies that captured the impacts of wildfire smoke and air quality on the local communities and their ongoing mental health condition. Regardless of the geographical location, the community 
members suffer from post-traumatic disorder and depression because of the wildfire incident they experienced earlier. The lingering effect of experiencing a significant traumatic event tends to take a massive toll on the survey respondents' mental health and well-being. The three significant mental health symptoms the individual experience are depression, PTSD, and sadness. The detailed findings of the quantitative studies on the intersection of mental health and wildfire are outlined in appendix 2.

I examined 23 qualitative studies, the bulk of which focused on the effects of wildfires on community members and the mental health issues that resulted in California. Like those in quantitative studies, participants in these qualitative research report substantial mental health consequences due to exposure to wildfires, poor air quality, and smokes.

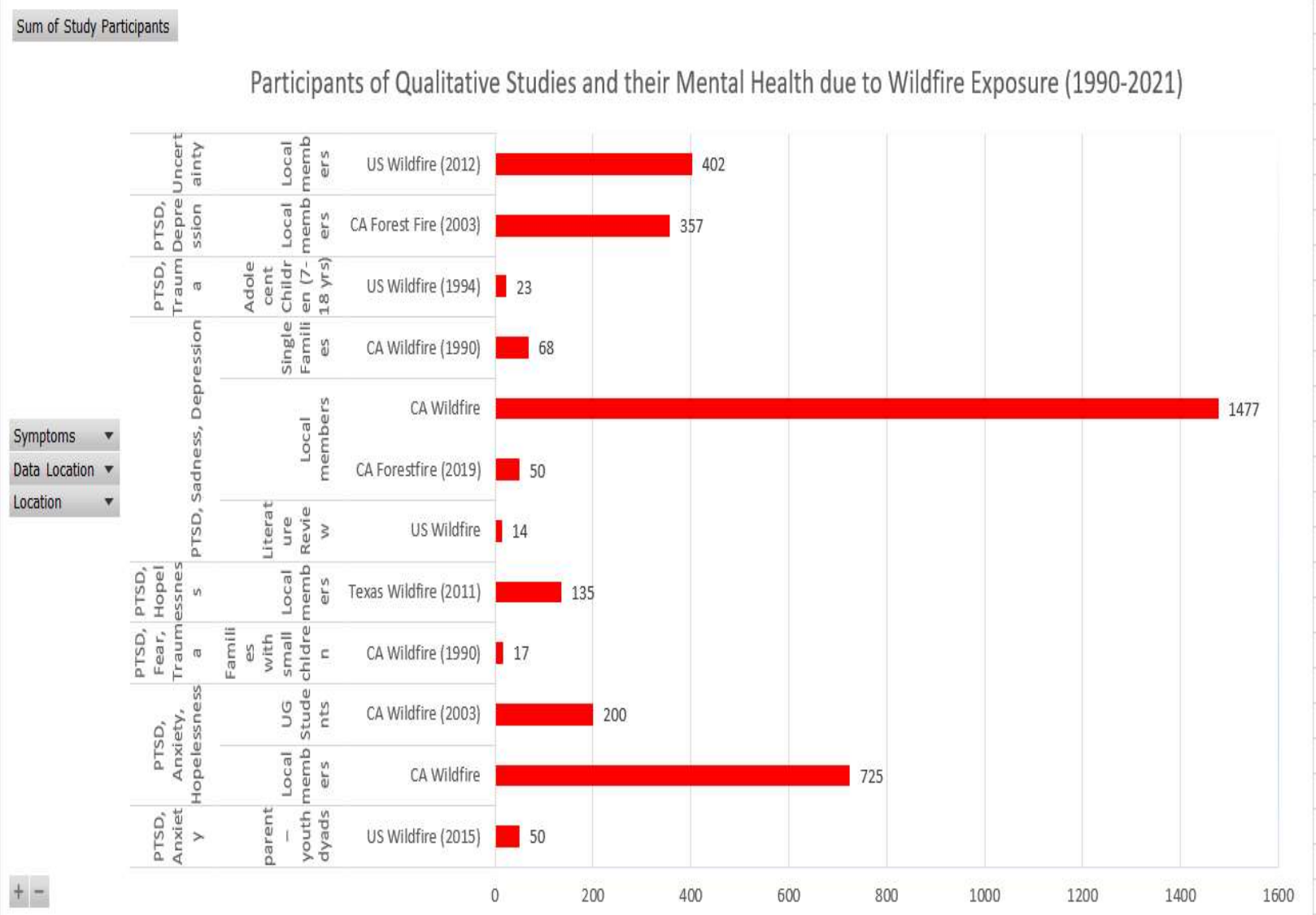

Figure 4: The Cumulative Findings of Qualitative Studies on Wildfire and Mental health 
Figure 4 summarizes the findings from qualitative research that explored and recorded the impact of wildfire exposure on study participants' mental health and well-being. The collection of qualitative studies conducted in-person interviews brought rich data and lived experiences of the study participants and how they have navigated the post-wildfire situations in their daily lives (Afifi et al., 2012; Felix et al., 2015; Jones et al., 1994, 2002; Marshall et al., 2007; R et al., 2016; Scher \& Ellwanger, 2009; Stern, 2020). Almost 90 percent of the participants experience some form of PTSD and anxiety due to the wildfire exposure.

\begin{tabular}{|c|c|c|}
\hline Most Afected Population & Symptoms & Location \\
\hline \multicolumn{2}{|c|}{$\Theta$ Female adolecents, non-white adolecen $\boxminus$ PTSD, Trauma } & US Wildfire (1994) \\
\hline$\Theta$ Female, Minority Status & \multicolumn{2}{|c|}{$\ominus$ PTSD, Anxiety, Hopelessnє CA Wildfire (2003) } \\
\hline Female, Minority Status & $\ominus$ PTSD, Depression & CA Forest Fire (2003) \\
\hline$\Theta$ General & \multicolumn{2}{|c|}{$\boxminus$ PTSD, Anxiety, Hopelessn؛ CA Wildfire } \\
\hline General & \multicolumn{2}{|c|}{$\Theta$ PTSD, Sadness, Depressior US Wildfire } \\
\hline General & $\Theta$ Uncertainty & US Wildfire (2012) \\
\hline$\Theta$ General, Minorties, farm workers & \multicolumn{2}{|c|}{$\Theta$ PTSD, Sadness, Depressioi CA Forestfire (2019) } \\
\hline$\Theta$ Migrant workers, Adults, & $\ominus$ PTSD, Hopelessness & Texas Wildfire (2011) \\
\hline$\Theta$ Mother, Minority members & $\ominus$ PTSD, Fear, Trauma & CA Wildfire (1990) \\
\hline Mother, Minority members & \multicolumn{2}{|c|}{$\boxminus$ PTSD, Sadness, Depressior CA Wildfire (1990) } \\
\hline$\Theta$ youth & $\boxminus$ PTSD, Anxiety & US Wildfire (2015) \\
\hline$\Theta$ youth children & \multicolumn{2}{|c|}{ ĐPTSD, Sadness, Depressioı CA Wildfire } \\
\hline
\end{tabular}

Figure 5: Most affected populations with mental health symptoms

Wildfire has significantly influenced local inhabitants and their well-being during the previous thirty years, beginning in 1990. Minority and underprivileged females, teenage youth, and migrant farm workers are the most susceptible members of communities, facing additional layers of hurdles and hardships in handling post-wildfire exposure in their life. Almost all the study participants experienced some ongoing PTSD due to the exposure to the wildfire. The vulnerability determinants either facilitate these individuals in getting adequate help to recover and function better or create additional barriers in obtaining resources and health care support. 
Roughly $90 \%$ of farming employees in California were born outside of the United States, primarily in Mexico and Central America. Even though estimations might differ due to conflicting data sources, it is argued that more than half of those farmworkers are undocumented and severely lack access to health care. Undocumented farmworkers do not always enter the country without proper papers. For illustration, amid persistent health problems, several documented farmworkers find it impossible to renew their work visas due to lockdown, office closure, delay in processing the application, and financial difficulties to fund the renewal fees (Adey et al., 2021; Jordan, 2020; Moriarty, 2021; Moroz et al., 2020; Srinivas \& Sivaraman, 2021).

This research study finds a strong connection that starting from 1990, based on both quantitative and qualitative research approaches, the mental health of the non-white females and adolescents were most severely impacted due to the wildfire exposure. The top three symptoms are PTSD, anxiety, and fear. Furthermore, immigration status and gender play a crucial role in seeking professional help and healthcare support in treating these mental health conditions. It is no secret that the massive majority of those who harvest America's food are undocumented immigrants, essentially from Mexico, many of whom have been in the country for decades. As parents of American-born children, they have frequently lived for years with the danger of deportation hanging over their heads. It is often difficult for them to revisit their affected residence and go on with their lives.

The mental health of the parents affects the well-being of the children. A parent's mental condition increases the likelihood of their children developing psychological illnesses. The importance of parents' health on a child's well-being has also been underlined by study findings, as a negative interaction between parents and children's condition is most probable when both suffer from the same ailment (CDC, 2021; Kamis, 2021; Karimzadeh et al., 2017). 


\section{The Significance of the Study}

This exploratory comparative research study examines around 40 scholarly works and captures their research methodology, study findings, and limitations in investigating the link between mental health and wildfire exposure. The study delves further, emphasizing the effects of wildfires on Californian communities and how they have dealt with post-wildfire living. Undocumented female farmworkers experienced higher rates of anxiety, PTSD, despair, and fear of uncertainty based on the vulnerability factors compared to other study participants. Their children also endured secondary mental trauma and stress because of their parents' lack of access to resources, understanding the importance of good mental health, and asking for support.

The ongoing pandemic adds an extra layer of difficulties and restrictions for the farmworkers to seek help to recover from their wildfire exposure trauma and PTSD. Mezzadra and Stierl (2020) aptly capture the ongoing struggle and barriers faced by the immigrant communities and state,

"Migrants embody in the harshest way the contradictions and tensions surrounding the freedom of movement and its denial today. It is not surprising that in the current climate, they tend to become one of the first targets of the most restrictive measures. Migrant populations who moved, or still seek to move, across borders without authorisation in order to escape danger are subjected to confinement and deterrence measures that are legitimized by often spurious references to public safety and global health. Discriminatory practices that segregate in the name of safety turn those at risk into $a$ risk." (Mezzadra \& Stierl, 2021)

The right to seek professional help to recover from mental health symptoms after experiencing wildfires is always a matter of the intersectional identities of the individuals. But this is particularly the case when one group's mobilities are perceived as negatively affecting the health and well-being of another group (the host community); indeed, wild claims have been made by 
some of the political and influential elites that migrants are more prone to 'disease' have been critical to the history of immigration control and access to healthcare.

\section{Limitations of the Study}

The collaborative comparative analytical assessment on the effects of wildfire exposure on mental health well-being has several limitations. Time and resource constraints might be ascribed to the top few limits. More databases may have been incorporated to assess and comprehend the effects

of wildfire and smoke exposure on mental health syndrome. Time restrictions caused several of the shortcomings of this review. More extensive study and analysis would provide a more complex, nuanced, and insightful explanation of this continuing societal challenge.

\section{$\underline{\text { Key Policy Recommendations }}$}

The ongoing wildfire continues to affect the local communities and, based on the determinants of vulnerability, the female and young adolescents suffered most in terms of mental health and well-being. The lawmakers, policymakers, legislators, and policy analysts could consider the vulnerability determinants in developing and implementing social policies that enhance access to healthcare and public support resources for the underserved populations. Climate Crisis research groups might consider exploring a more focused approach in examining the prolonged wildfire exposure and smoke for the vulnerable communities, mother, children, and adolescents. I also vigorously promote implementing and expanding a new global cross-sector network to ensure data interoperability, bring relevant researchers, professionals, and decisionmakers together to catalyze awareness, productively place more emphasis on exploration, discovery, and scale-up localized adaptive intervention strategies. 


\section{Conclusion and Future Works}

Exploring the psychological impacts of wildfire exposure is critical as the frequency, length, and intensity of wildfires increase in the United States and worldwide due to climate change. As a result, fire seasons will be extended, resulting in more intense smoke, landscape damage, and a worsening of the well-being of California's vulnerable farm workers. It is critical to better characterize the mental health effects of wildfire exposure in terms of protecting these workers' health, including the impact on the mental health of smoke to protect communities, individual and situational exposure in children and adolescents, and the ability to contribute of place-attachment and solastalgia to mental wellbeing.

This comparative scoping analytical study finds that starting from 1990, the female migrant farmworkers are the most vulnerable populations during and after wildfires in California. The restrictive situations for the farmworkers are generational, and almost all the studies find that women and children are most vulnerable and lack the ability and support to heal their PTSD, trauma, and mental health symptoms due to the wildfire exposure in California. It is challenging for them to reach out to their local healthcare facilities to get support and assistance. Additionally, the ongoing health crisis escalates the overall situation and adds extra layers of immobility, uncertainty, and stress to get adequate professional help to reduce and recover from earlier wildfire exposure. Wildfires will continue to occur when communities move closer to nature or into previously woodland regions, posing a hazard to individual well-being and public health. Understanding the effects of wildfires on physical problems and mental health-related issues necessitates a public health response that is comprehensive, long-term, and as adaptable as the people it serves. A substantial amount of literature supports the effects of wildfires on mental 
health, but more research is needed on effective public health policies and rebuilding techniques that might maximize patient resilience post-wildfire.

The findings from my research tend to support the diagnosis that the vulnerability determinants play a crucial role in determining the level of access to mental health support to the local community members' who experienced wildfire exposure. The qualitative studies offer richer, nuanced, and relatable experiences from the study participants, aptly capturing limitations and barriers for the Californian farmworkers to acknowledge, understand, and reach out to get mental health support. My analysis and findings would contribute to developing more inclusive legislation and policies that facilitate the communities to get timely and adequate mental health support to mitigate the impacts of wildfire exposure. My research also advances the scientific and data-based notion that extended exposure to wildfire and smoke could cause severe mental health symptoms, impacting children and adolescents. Developing a more robust and functional healthcare framework that provides adequate mental health support with enhanced and localized accessibility to the communities exposed to wildfire creates more health equity and reduces mental health problems among our future generations. 


\section{Works cited:}

Adey, P., Hannam, K., Sheller, M., \& Tyfield, D. (2021). Pandemic (Im)mobilities. Mobilities, 16(1), 1-19. https://doi.org/10.1080/17450101.2021.1872871

Afifi, W. A., Felix, E. D., \& Afifi, T. D. (2012). The impact of uncertainty and communal coping on mental health following natural disasters. Anxiety, Stress, \& Coping, 25(3), 329-347. https://doi.org/10.1080/10615806.2011.603048

Afzal, M. H. B. (2019). Power and Trade Agreements between Developed and Developing Countries [Preprint]. Comparative Politics. https://doi.org/10.33774/apsa/2019/xzz4z

Afzal, M. H. B. (2020). The Impact of Persistent Climate Crisis on the mobility of Rural Bangladeshi Communities: How Far Would They be Able to Move and Sustain? https://doi.org/10.33774/apsa-2020-48fv0

Afzal, M. H. B. (2021a). An Empirical Analysis of how Internet Access Influences Public Opinion towards Undocumented Immigrants and Unaccompanied Children. ArXiv:2110.07489 [Econ, q-Fin]. http://arxiv.org/abs/2110.07489

Afzal, M. H. B. (2017). Sustainable Development of Rural Communities in Bangladesh by Integrating Mobile Internet and Agent Banking Technology. In R. Benlamri \& M. Sparer (Eds.), Leadership, Innovation and Entrepreneurship as Driving Forces of the Global Economy (pp. 361-370). Springer International Publishing.

Afzal, M. H. B. (2021b). The Detrimental Impacts of Restrictive Immigration Policies During Global Health Crises: Health Inequities and Mobility Crisis. 2021 IEEE Technology Engineering Management Conference - Europe (TEMSCON-EUR), 1-6. https://doi.org/10.1109/TEMSCON-EUR52034.2021.9488615 
Brook, L., \& Constible, J. (2020, September 14). Treat Farmworkers as Essential, not Sacrificial. NRDC. https://www.nrdc.org/experts/lena-brook/treat-farmworkers-essential-notsacrificial

Care, I. of M. (US) C. on U. and E. R. and E. D. in H., Smedley, B. D., Stith, A. Y., \& Nelson, A. R. (2003). The Healthcare Environment and Its Relation to Disparities. In Unequal Treatment: Confronting Racial and Ethnic Disparities in Health Care. National Academies Press (US). https://www.ncbi.nlm.nih.gov/books/NBK220362/

Castillo, A. (2020, April 1). Farmworkers face coronavirus risk: "You can't pick strawberries over Zoom." Los Angeles Times. https://www.latimes.com/california/story/2020-0401/california-farmworkers-coronavirus

CDC. (2021, April 23). Mental health of children and parents-A strong connection. Centers for Disease Control and Prevention. https://www.cdc.gov/childrensmentalhealth/features/mental-health-children-andparents.html

Coaston, J. (2019, May 20). The intersectionality wars. Vox. https://www.vox.com/thehighlight/2019/5/20/18542843/intersectionality-conservatism-law-race-genderdiscrimination

Dubrow, R. (2021, September 22). SECTION 4: Overview of Adverse Health Impacts of Climate Change (Part 2): Determinants of Vulnerability.

EPA. (2020). Technical Documentation: Wildfires (p. 15).

Felix, E., Afifi, T., Kia-Keating, M., Brown, L., Afifi, W., \& Reyes, G. (2015). Family functioning and post-traumatic growth among parents and youth following wildfire 
disasters. American Journal of Orthopsychiatry, 85(2), 191-200.

https://doi.org/10.1037/ort0000054

Galarneau, C. (2013). Farm labor, reproductive justice: Migrant women farmworkers in the US. Health and Human Rights, 15(1), 17.

Jones, R. T., Ribbe, D. P., \& Cunningham, P. (1994). Psychosocial correlates of fire disaster among children and adolescents. Journal of Traumatic Stress, 7(1), 117-122. https://doi.org/10.1002/jts.2490070112

Jones, R. T., Ribbe, D. P., Cunningham, P. B., Weddle, J. D., \& Langley, A. K. (2002). Psychological Impact of Fire Disaster on Children and Their Parents. Behavior Modification, 26(2), 163-186. https://doi.org/10.1177/0145445502026002003

Jordan, M. (2020, April 2). Farmworkers, Mostly Undocumented, Become 'Essential' During Pandemic. The New York Times. https://www.nytimes.com/2020/04/02/us/coronavirusundocumented-immigrant-farmworkers-agriculture.html

Kamis, C. (2021). The Long-Term Impact of Parental Mental Health on Children's Distress Trajectories in Adulthood. Society and Mental Health, 11(1), 54-68. https://doi.org/10.1177/2156869320912520

Karimzadeh, M., Rostami, M., Teymouri, R., Moazzen, Z., \& Tahmasebi, S. (2017). The association between parental mental health and behavioral disorders in pre-school children. Electronic Physician, 9(6), 4497-4502. https://doi.org/10.19082/4497

Marshall, G. N., Schell, T. L., Elliott, M. N., Rayburn, N. R., \& Jaycox, L. H. (2007). Psychiatric Disorders Among Adults Seeking Emergency Disaster Assistance After a WildlandUrban Interface Fire. PSYCHIATRIC SERVICES, 58(4), 6. 
Mezzadra, S., \& Stierl, M. (2021). What happens to freedom of movement during a pandemic? https://www.opendemocracy.net/en/can-europe-make-it/what-happens-freedommovement-during-pandemic/

Moriarty, A. (2021). Immigrant Farmworkers and America's Food Production-5 Things to Know. https://www.fwd.us/news/immigrant-farmworkers-and-americas-food-production5-things-to-know/

Moroz, H., Shrestha, M., \& Testaverde, M. (2020). Potential Responses to the COVID-19 Outbreak in Support of Migrant Workers [Working Paper]. World Bank. https://doi.org/10.1596/33625

NASA. (2021, October 4). What's Behind California's Surge of Large Fires? [Text.Article]. https://earthobservatory.nasa.gov/images/148908/whats-behind-californias-surge-oflarge-fires

NICC. (2020). Wildland Fire Summary and Statistics Annual Report (2020).

NPS. (2020, December 12). Wildfire Causes and Evaluations (U.S. National Park Service). https://www.nps.gov/articles/wildfire-causes-and-evaluation.htm

Pierre-Louis, K., \& Schwartz, J. (2021, July 16). Why Does California Have So Many Wildfires? The New York Times. https://www.nytimes.com/article/why-does-california-havewildfires.html

R, K., A, F., F, Z., HaywoodTracy, W, J., \& A, H. (2016). Longitudinal Community Assessment for Public Health Emergency Response to Wildfire, Bastrop County, Texas. Health Security. https://doi.org/10.1089/hs.2015.0060 
Rosenberg, L. (2020, September 30). Here's Why California Seems to Be the Victim of So Many Devastating Wildfires. Green Matters. https://www.greenmatters.com/p/why-doescalifornia-have-so-many-wildfires

Scher, C. D., \& Ellwanger, J. (2009). Fire-related cognitions moderate the impact of risk factors on adjustment following wildfire disaster. Journal of Anxiety Disorders, 23(7), 891-896. https://doi.org/10.1016/j.janxdis.2009.05.007

Seattle Times. (2020, August 21). Why does California have so many wildfires? 4 key reasons. The Seattle Times. https://www.seattletimes.com/nation-world/why-does-california-haveso-many-wildfires-4-key-reasons/

Short, K. C. (2020). Spatial wildfire occurrence data for the United States, 1992-2015 [FPA_FOD_20170508] (4th Edition) [Data set]. Forest Service Research Data Archive. https://doi.org/10.2737/RDS-2013-0009.4

Srinivas, S., \& Sivaraman, S. (2021). Understanding Relevant Sustainable Development Goal Targets Related to Labour Migration in the Association of Southeast Asian Nations During the Coronavirus Disease Pandemic. https://think-asia.org/handle/11540/13761

Stern, J. (2020, July 20). A Mental-Health Crisis Is Burning Across the American West. The Atlantic. https://www.theatlantic.com/health/archive/2020/07/mental-health-aftermathcalifornia-wildfires/608656/

Verisk. (2020, December 12). 2021 Verisk Wildfire Risk Analysis. Verisk. https://www.verisk.com/insurance/campaigns/location-fireline-state-risk-report/ 
Appendix 1: Full Scope of the Research(Intersection of CA Wildfire, Mental Health, and Vulnerability Determinants:

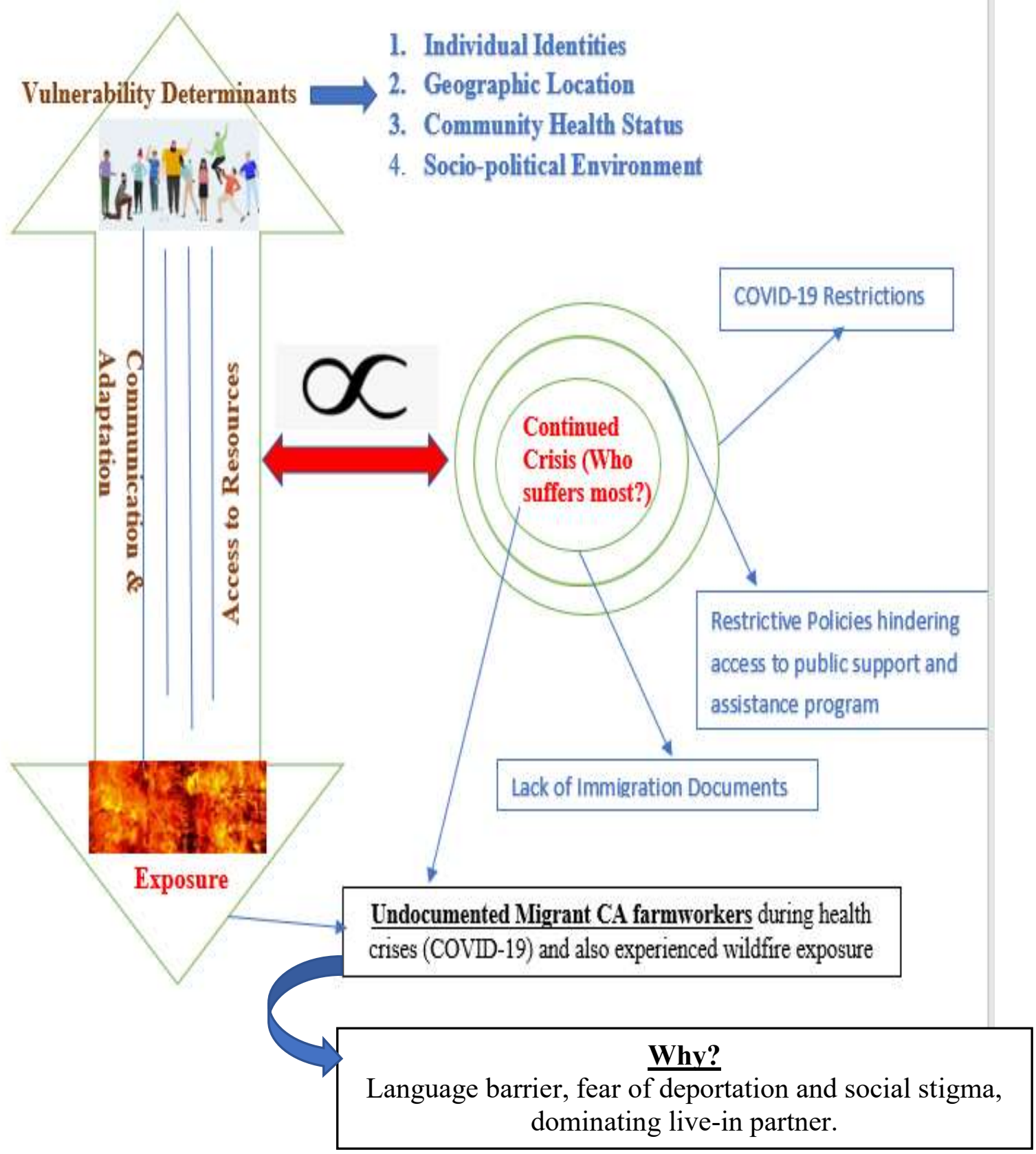

Figure: The full scope of the study 
Appendix 2: List of Quantitative Studies and their findings:

\begin{tabular}{|c|c|c|c|c|c|}
\hline Studies & Location & Data Location & Associatior & Symptoms & Population \\
\hline Camilleri (2010) & Australia Wildfire & Mail-in-Survey & 1 (Yes) & Fear,Anxiety & Local Community members \\
\hline Engebretson (2016) & CAWildfire & Mali-in-Survey & 1 (Yes) & Fear,Anxiety & Local Community members \\
\hline Vincent, 2018 & Canadian Wildfire & Medical Billing Data & $\mathrm{O}(\mathrm{N} N)$ & Not Significant & Local Community members \\
\hline Marshall (2007) & CA Forest Fire & Local memebrs & 1 (Yes) & PTSD,Depression & Local Community members \\
\hline Isorna (2011) & Spain Wildfire & local members & 1 (Yes) & PTSD,Depression & Local Community members \\
\hline Tally (2013) & San Diego & Mail-in-Survey & 1 (Yes) & PTSD,Depression & Local Community members \\
\hline Ho (2014) & Singapore Wildfire & Local members & 1 (Yes) & PTSD,Depression & Local Community members \\
\hline Pretto (2015) & Malaysian Wildfire & local members & 1 (Yes) & PTSD, Sadness, Depression & Local Community members \\
\hline Reid (2016) & CAWildfire & local members & 1 (Yes) & PTSD, Sadness, Depression & Local Community members \\
\hline $\operatorname{Tan}(2019)$ & Singapore Wildfire & local members & 1 (Yes) & PTSD, Sadness, Depression & Local Community members \\
\hline Stern (2020) & CAForestfire & local members & 1 (Yes) & PTSD, Sadness, Depression & Local Community members \\
\hline
\end{tabular}

Table 1: Summary findings of the Quantitative studies focus on wildfire and mental health

\begin{tabular}{|c|c|c|}
\hline Symptoms & Location & Sum of Days \\
\hline$\boxminus$ Fear,Anxiety & Australian Wildfire (2004) & 30 \\
\hline$\exists$ Not Significant & CA Wildfire (1988) & 17 \\
\hline Not Significant & Canadian Wildfire (2005) & 14 \\
\hline$\exists$ PTSD, Sadness, Depressic & c CA Forestfire (2019) & 14 \\
\hline PTSD, Sadness, Depressic & c CA Wildfire (2016) & 14 \\
\hline PTSD, Sadness, Depressic & c Malaysian Wildfire (2015) & 14 \\
\hline PTSD, Sadness, Depressic & c Singapore Wildfire (2018) & 14 \\
\hline$\boxminus$ PTSD,Depression & CA Forest Fire (2006) & 90 \\
\hline PTSD,Depression & Singapore Wildfire (2014) & 14 \\
\hline PTSD,Depression & Spain Wildfire (2009) & 14 \\
\hline
\end{tabular}

Table 2: Summary findings of the Quantitative studies focus on wildfire and mental health Symptoms 


\section{Appendix 3: List of Qualitative Studies and their findings:}

\begin{tabular}{|c|c|c|c|c|c|c|c|}
\hline Year & Studies & Location & Study Participants & Data Location & Mode of Data Collection & Symptoms & Population \\
\hline 1994 & Jones (1994) & US Wildfire (1994) & 23 & Adolecent Children ( $7-18 \mathrm{yrs})$ & In-person Interviews & PTSD, Trauma & male adolecents, non-white adolecents \\
\hline 2002 & Jones (2002) & CA Wildfire (1990) & 68 & Single Families & In-person Interviews & PTSD, Sadness, Depression & Mother, Minority members \\
\hline 2003 & Jones (2003) & CA Wildfire (1990) & 17 & Families with small children & In-person Interviews & PTSD, Fear, Trauma & Mother, Minority members \\
\hline 2007 & Marshall(2007) & CA Forest Fire (2003) & 357 & Local members & Survey Questionaire & PTSD, Depression & Female, Minority Status \\
\hline 2009 & and Ellwanger'( & CA Wildfire (2003) & 200 & UG Students & In-person Interviews & PTSD, Anxiety, Hopelessness & Female, Minority Status \\
\hline 2012 & Afifi et al (2012) & US Wildfire (2012) & 402 & local members & Phone Interview & Uncertainty & General \\
\hline 2015 & Felix (2015) & US Wildfire (2015) & 50 & parent-youth dyads & In-person Interviews & PTSD, Anxiety & youth \\
\hline 2016 & $\operatorname{Reid}(2016)$ & US Wildfire & 14 & Literature Review & Literature Review & PTSD, Sadmess, Depression & General \\
\hline 2016 & $\operatorname{Kirsch}(2016)$ & Texas Wildfire (2011) & 135 & Local members & In-person Interviews & PTSD, Hopelessness & Migrant workers, Adults, \\
\hline 2020 & Stern (2020) & CA Forestfire (2019) & 50 & local members & In-person Interviews & PTSD, Sadness, Depression & General \\
\hline 2020 & itz-Picciotto (20: & CA Wildfire & 1477 & Local Members & In-person Interviews & PTSD, Sadness, Depression & youth children \\
\hline 2021 & Silveira (2021) & CA Wildifire & 725 & Local members & In-person Interviews & PTSD, Anxiety, Hopelessness & General \\
\hline
\end{tabular}

Table 1: Summary findings of the Qualitative studies focus on wildfire and mental health

\begin{tabular}{|c|c|c|c|}
\hline \multirow{2}{*}{$\begin{array}{l}\text { Symptoms } \\
\boxminus \text { PTSD, Anxiety }\end{array}$} & Data Location & Location & Sum of Study Participants \\
\hline & $\Theta$ parent-youth dyads & US Wildfire (2015) & 50 \\
\hline \multicolumn{2}{|c|}{$\boxminus$ PTSD, Anxiety, Hopelessn؛ $\boxminus$ Local members } & CA Wildfire & 725 \\
\hline \multicolumn{2}{|c|}{ PTSD, Anxiety, Hopelessnє $\boxminus$ UG Students } & CA Wildfire (2003) & 200 \\
\hline$\boxminus$ PTSD, Fear, Trauma & \multicolumn{2}{|c|}{$\Xi$ Families with small chldren CA Wildfire (1990) } & 17 \\
\hline$\boxminus$ PTSD, Hopelessness & $\Theta$ Local members & Texas Wildfire (2011) & 135 \\
\hline \multicolumn{2}{|c|}{$\Theta$ PTSD, Sadness, Depressiol $\boxminus$ Literature Review } & US Wildfire & 14 \\
\hline \multicolumn{2}{|c|}{ PTSD, Sadness, Depressiol $\boxminus$ Local members } & CA Forestfire (2019) & 50 \\
\hline PTSD, Sadness, Depressiol & Local members & CA Wildfire & 1477 \\
\hline \multicolumn{2}{|c|}{ PTSD, Sadness, Depressiol $\boxminus$ Single Families } & CA Wildfire (1990) & 68 \\
\hline$\exists$ PTSD, Trauma & \multicolumn{2}{|c|}{$\exists$ Adolecent Children (7-18 y US Wildfire (1994) } & 23 \\
\hline$\boxminus$ PTSD,Depression & $\ominus$ Local members & CA Forest Fire (2003) & 357 \\
\hline$\boxminus$ Uncertainty & $\boxminus$ Local members & US Wildfire (2012) & 402 \\
\hline
\end{tabular}

Table 2: Summary findings of the Qualitative studies focus on wildfire and mental health Symptoms 


\section{Appendix 04: Vulnerable Populations vs. Count of Symptoms}

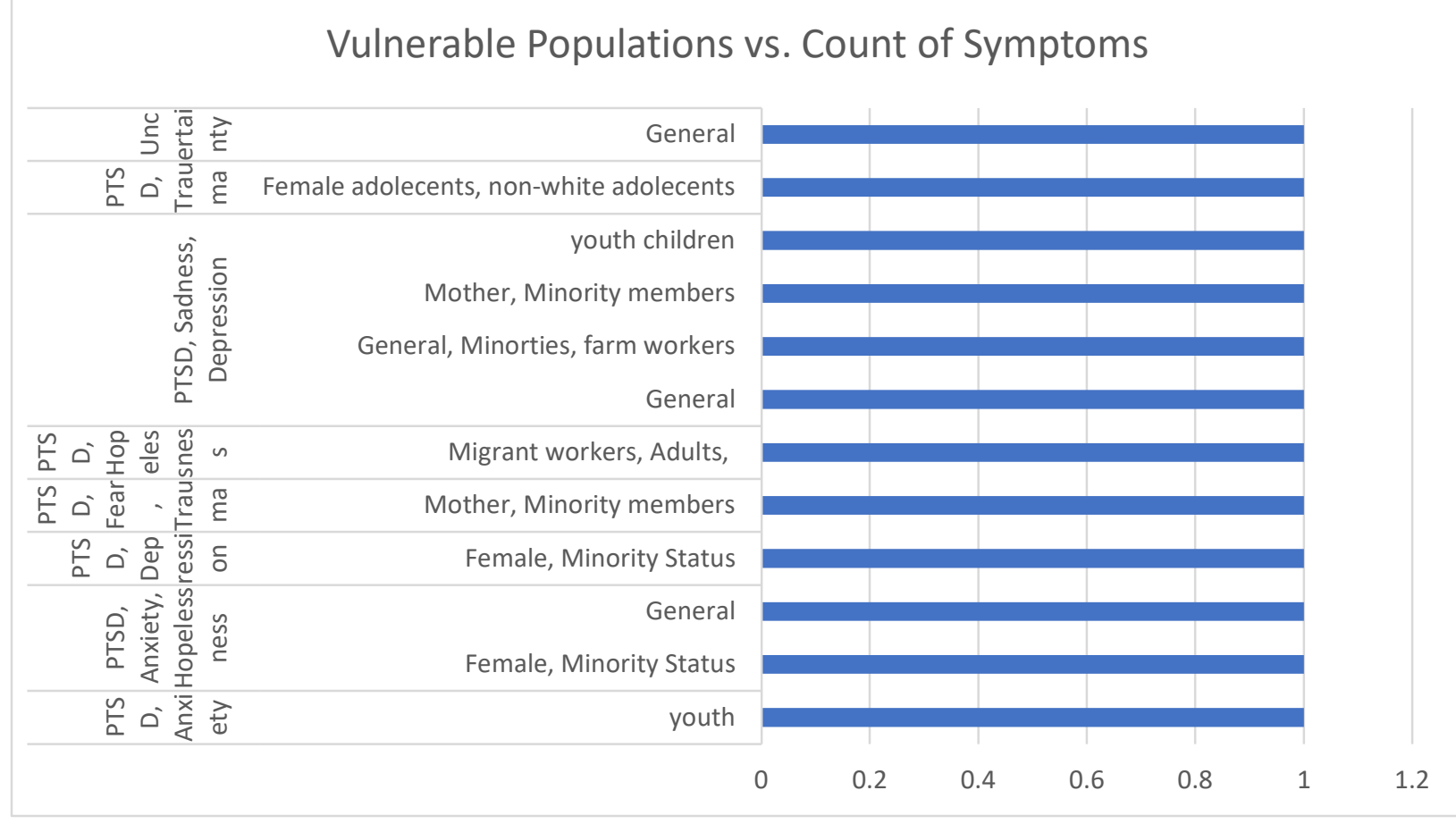

Figure: Vulnerable Populations vs. Count of Symptoms

\begin{tabular}{|c|c|c|c|}
\hline Symptoms & $\checkmark$ & Most Afected Population & 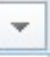 \\
\hline \multicolumn{2}{|l|}{$\boxminus$ PTSD, Anxiety } & \multicolumn{2}{|l|}{ youth } \\
\hline \multicolumn{4}{|c|}{$\Theta$ PTSD, Anxiety, Hopelessnє Female, Minority Status } \\
\hline \multicolumn{4}{|c|}{ PTSD, Anxiety, Hopelessn؛ General } \\
\hline$\Theta$ PTSD, Depression & & \multicolumn{2}{|l|}{ Female, Minority Status } \\
\hline$\Theta$ PTSD, Fear, Trauma & & \multicolumn{2}{|l|}{ Mother, Minority members } \\
\hline$\Theta$ PTSD, Hopelessness & & \multicolumn{2}{|l|}{ Migrant workers, Adults, } \\
\hline \multicolumn{4}{|c|}{$\Theta$ PTSD, Sadness, Depressior General } \\
\hline \multicolumn{4}{|c|}{ PTSD, Sadness, Depressior General, Minorties, farm workers } \\
\hline \multicolumn{4}{|c|}{ PTSD, Sadness, Depressior Mother, Minority members } \\
\hline \multicolumn{4}{|c|}{ PTSD, Sadness, Depressior youth children } \\
\hline$\Theta$ PTSD, Trauma & & Female adolecents, non-white adolecents & \\
\hline$\Theta$ Uncertainty & & General & \\
\hline
\end{tabular}

Figure: $\underline{\text { Symptoms vs. Most affected Populations }}$ 